\title{
Pediatric Head Injury Caused by Off-Road Vehicle Accidents
}

\author{
E.R. Cardoso and Alexander Pyper
}

\begin{abstract}
Morbidity and mortality from pediatric head injuries associated with the use of off-road vehicles are increasing. We reviewed all such injuries admitted to acute care hospitals in the two largest urban centers in Manitoba between April 1979 and August 1986. Of 375 injured children, 83 suffered head injury, 70 boys and 13 girls. Ages ranged from 2 to 15 years, with a mean of 10.4 years. Head injury was defined as any injury involving face, scalp or nervous system. Dirtbikes were implicated in 34 accidents, snowmobiles in 28, 3-wheel ATV's in 19, and 4-wheel ATV's in 2 . About $85 \%$ of accidents occurred in a rural setting. Loss of vehicle control was the most common cause of injury. Alcohol or drug abuse were not factors. Fifty $(60.2 \%)$ patients suffered loss of consciousness, prolonged in 6 $(7.2 \%)$. All head-injured children also suffered at least one associated injury, mainly involving the musculoskeletal system. Associated spinal injury occurred in $18 \%$. The average hospital stay was 13 days. Three (3.6\%) patients died as a result of head injury.
\end{abstract}

RÉSUMÉ: Blessures à la tête, dans la population pédiatrique, causées par des accidents impliquant des véhicules tout terrain La morbidité et la mortalité dues à des blessures à la tête en relation avec l'utilisation de véhicules tout terrain sont à la hausse. Nous avons revu tous les cas de ces traumatismes qui ont été admis dans un hôpital de soins aigus dans deux des plus grands centres urbains du Manitoba entre avril 1979 et août 1986. Parmi les 375 enfants blessés, 83 avaient subi des blessures à la tête, soit 70 garçons et 13 filles, dont l'âge variait de 2 à 15 ans, l'âge moyen étant de 10.4 ans. Un traumatisme à la tête était défini comme n'importe quelle blessure au visage, au cuir chevelu ou au système nerveux. Les motos tout terrain étaient impliquées dans 34 accidents, les moto-neige dans 28 , les véhicules tout terrain à 3 roues dans 19 et les véhicules tout terrain à 4 roues dans 2 . Environ $85 \%$ des accidents se sont produit à la compagne. La cause la plus fréquente de blessures était la perte de contrôle du véhicule. Labus d'alcool ou de drogues n'était pas en cause. Cinquante (60.2\%) patients avaient subi une perte de conscience qui a été de longue durée dans 6 cas $(7.2 \%)$. Tous les enfants qui ont subi des blessures à la tête ont également subi au moins une autre blessure, impliquant dans la majorité des cas le système musculosquelettique. Dix-huit pourcent des cas présentaient une lésion associée au niveau de la colonne vertébrale. La durée moyenne du séjour hospitalier était de 13 jours. Trois patients sont décédés à la suite de blessures à la tête.

Can. J. Neurol. Sci. 1989; 16:336-339

Head trauma is a major cause of morbidity and mortality in children. It accounts for an estimated 220 injuries per 100,000 children per year in North America. ${ }^{1}$ Head injury is also responsible for about half of the accidental deaths in children and about one-quarter of all deaths in the pediatric population. ${ }^{1}$ It is estimated that the mortality rate from pediatric head injuries in North America is around 10 per 100,000 children. 1,2 Furthermore, half of the pediatric deaths due to accidents are caused by motor vehicles. ${ }^{1}$

Off-road vehicles include snowmobiles, off-road motorcycles (dirtbikes, minibikes and trailbikes) and 3- or 4-wheeled all-terrain vehicles (ATV's). Despite a recent progressive increase in the number of pediatric head injuries caused by offroad vehicles, this type of head injury has not been formally studied. 3,5 We conducted a retrospective review of all cases of pediatric head injuries, admitted to 8 hospitals in the two largest cities of Manitoba.

\section{Clinical Material}

The two largest cities in the Province of Manitoba, Canada hold a total population of 659,529 , representing $62.5 \%$ of the total provincial census. There are 8 acute care hospitals that manage pediatric trauma in the two cities. We reviewed all medical records of children who sustained injury from off-road vehicle accidents and were admitted to those 8 hospitals, from April 1979 to August 1986. Of the 375 injured patients admitted to hospital, 83 sustained a head injury $(22.13 \%)$. Head injury was defined as any injury to face, scalp and nervous system. The upper age limit was 15 years.

From the Department of Surgery, University of Manitoba, Winnipeg, Manitoba

Received November 22, 1988. Accepted in final form March 7, 1989

Reprint requests to: Dr. E.R. Cardoso, Cerebral Hydrodynamics Laboratory, Health Sciences Centre, MS-771, 820 Sherbrook Street, Winnipeg, Manitoba, Canada R3A 1R9 
Pediatric mortality data were obtained from provincial mortality records for the same period of time, which included year of death and type of vehicle involved.

\section{RESULTS}

\section{Age and Sex}

Of the 83 head injured patients, $70(81.4 \%)$ were boys and $13(18.6 \%)$ were girls. The boys' ages ranged from 3-15 years with an average of 10.7 years, while girls ranged from 2-15 years, averaging 10.4 years.

\section{Type of Off-Road Vehicle}

Thirty-four cases (41.08\%) involved minibikes/dirtbikes; 28 cases $(33.7 \%)$ implicated snowmobiles; 3-wheel ATV's accounted for $19(22.9 \%)$ cases; and $2(2.4 \%)$ of the children had accidents while riding 4-wheel ATV's.

\section{Accidents by Year, Season and Time of Day}

The yearly number of head injuries increased over the study period, from 5 patients in 1980 to 23 patients in 1985 (Figure 1).

Seasonal distribution showed a larger number of accidents in the summer months except for snowmobiling, which can be practiced for six months of the year in Manitoba (Figure 2). ATV's can be used all year round.

Accurate recording of the timing of the accident was obtained in $61(72.7 \%)$ cases. Eighty-two percent of the accidents occurred during the daylight hours, in agreement with

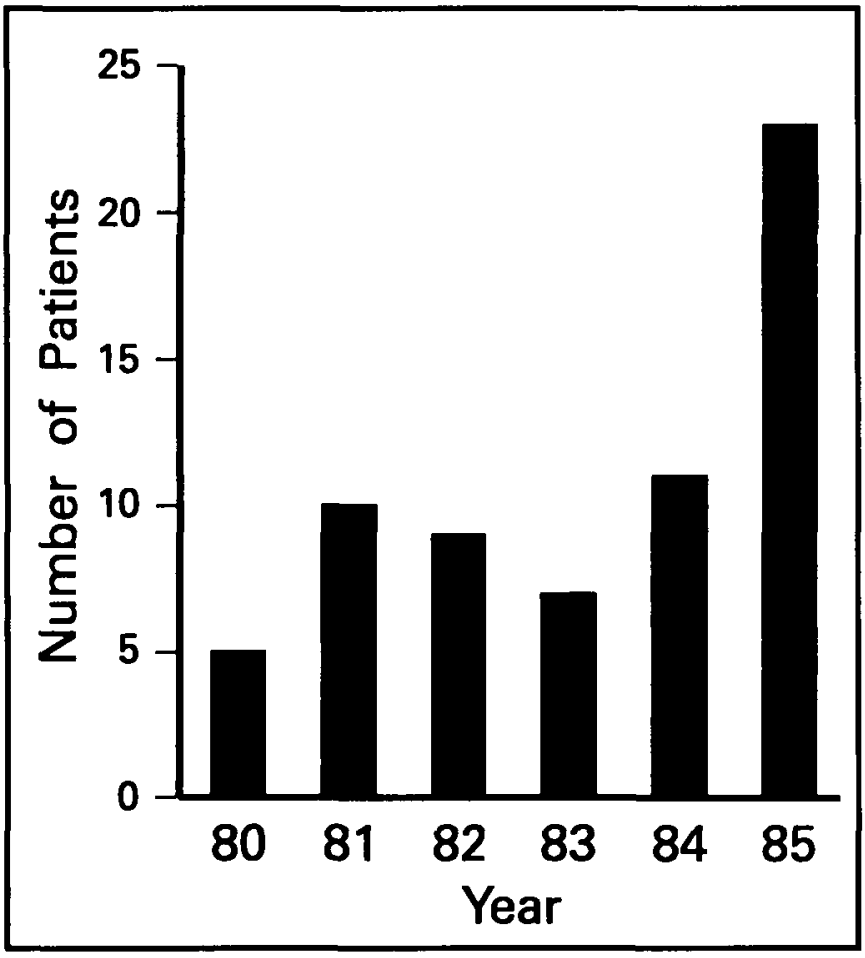

Figure I - Yearly incidence of head injuries caused by off-road vehicle accidents. Only complete years are included because of seasonal variations of the number of accidents. Thus, the inclusion of incomplete years, involving different seasons, might introduce artefactual values.

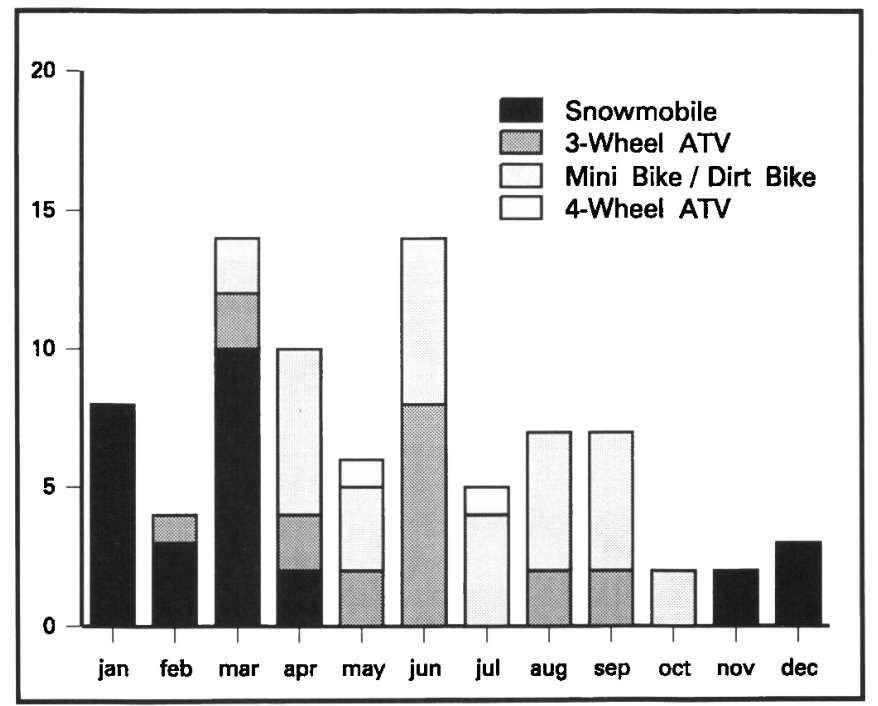

Figure 2 - Seasonal distribution of head injuries according to the type of off-road vehicle involved.

other reviews. ${ }^{6-8}$ The average vehicle speed at the time of accident, as estimated from 6 cases was $18.3 \mathrm{mph}$.

\section{Mechanism of Injury}

Loss of vehicle control which occurred in $76 \%$ of the accidents, was the most common mechanism of injury, followed by collision. This finding also concurs with the work of others.9-16

Only $7.2 \%$ of injured children reported the use of helmets. However information on helmet use was recorded in only $12 \%$ of the charts reviewed. Half of them suffered a severe head injury, with prolonged coma.

Accidents involving multiple riders accounted for 14 cases $(16.9 \%)$. This is legal for snowmobile use, but illegal with the other types of off-road vehicles. Eighty-five and a half percent of the injured children were drivers. The majority of accidents $(85 \%)$ occurred in rural settings.

\section{Severity of Head and Associated Injuries}

Fifty patients $(60.2 \%)$ suffered loss of consciousness, lasting only seconds in 14 patients, minutes in 30 patients and extended coma in 6. Glasgow Coma Scale score on admission was only recorded in 13 patients.

Skull fractures were present in $14(17 \%)$ patients and 49 (59\%) children suffered lacerations and abrasions of scalp and face. There were 10 cases $(12 \%)$ of tooth avulsion, 17 cases $(20.5 \%)$ of facial bone fractures, and 8 cases $(9.6 \%)$ of eye injury.

Cerebral contusion was observed in 9 cases $(10.8 \%)$ and intracerebral hematomas in 5 cases $(6 \%)$. No subdural hematomas were diagnosed, as they are infrequent in this age group. ${ }^{17}$ One patient presented traumatic VIth cranial nerve palsy. No extradural hematomas were encountered.

There were a total of 98 associated fractures, $71.4 \%$ of which were displaced and $6.1 \%$ compound. Twenty-nine head injured patients $(35 \%)$ suffered multiple associated fractures. Fifteen patients (18\%) showed associated spinal injuries, including fractures in 7 cases, cervical spine "whiplash" in 5, $\mathrm{C} 1-\mathrm{C} 2$ subluxation in one case and lumbar contusion in two cases. 
Fifty-six (67.5\%) patients underwent surgical procedure under general anesthetic, involving the head in 13 cases $(15.7 \%)$. The average hospital stay was 12 days for boys and 14 days for girls.

\section{Discussion}

\section{Off-Road Vehicles}

The use of motorized off-road vehicles in remote areas has proved to be very practical for farming, mining, trapping and logging. Their recreational applications have also become increasingly popular among children. ${ }^{3-5}$. 18-20 The main types of off-road vehicles used by the young include snowmobiles, offroad motorcycle (mini-bikes, trailbikes or dirtbikes), and 3 or 4wheel ATV's. Numerous models of snowmobile are available, some weighing up to $300 \mathrm{~kg}$. and capable of speeds of up to 160 $\mathrm{km} / \mathrm{h} .{ }^{7}$ Of the 2-wheel off-road vehicles, minibikes are the simplest, smallest and lightest, weighing less than $45 \mathrm{~kg} .{ }^{9}$ Trailbikes or dirtbikes are considerably larger, with more power and improved capabilities over rough surfaces. All-terrain vehicles have three or four low pressure tires and are capable of reaching speeds of up to $100 \mathrm{~km} / \mathrm{hr}$. Instability of the 3-wheel ATV in sharp turns or uphill driving is related to a high center of gravity, absent independent suspension, and lack of rear wheel differential. ${ }^{21}$

The incidence of injuries related to all types of off-road vehicle use is rising. ${ }^{3-5,22}$ Furthermore, several pediatric deaths have also been reported in association with their use. 9,23 Childhood ATV-inflicted injuries and deaths have been more widely reported. In Canada alone there were 25 ATV related deaths in 1985.19

Despite a large number of publications dealing with pediatric injuries caused by one specific type of off-road vehicle no report has yet investigated the characteristics of head injuries caused by those vehicles. $10,15,16,24$ Our retrospective review of 375 pediatric patients hospitalized after accidents from off-road vehicles uncovered 83 head injured children. This $22.1 \%$ rate of head trauma involvement is similar to the $21.4 \%$ reported by Heilman et al 25 for motorcycle accidents. Furthermore, the severity of head injury as well as the number of associated injuries was comparable to motorcycle injured patients. 25

\section{Causes of Pediatric Head Injury}

Changes in the types of accidents responsible for pediatric head injuries over the last 30 years reflect differences in social attitudes, as well as the increasing affluence of North American society over that period of time. For instance, there has been a gradual increase in the number of reported motorcycle accidents over many years, while only very recently have off-road vehicle accidents been noted. Extensive reviews of 4,465 pediatric head injuries from 1954 to 1962,26 as well as of 384 other cases from 1960 to 196927 do not specifically mention motorcycle accidents as the cause of head injuries. On the other hand, the reviews by Annegers et al, extending from 1935 to 1974, disclosed 8 motorcycle-related accidents, accounting for only $1.2 \%$ of 661 pediatric head injuries. 1,2 Recently, Cooper acknowledged the existence of an increasing number of head injuries related to off-road vehicle accidents and estimated that many are never reported. ${ }^{28} \mathrm{Kriel}$ et al reported 7 cases of pediatric head injury caused by all-terrain-vehicle accidents. There were selected from 93 consecutive head injuries admitted between 1979 and 1985.3

Our results also showed an increase in the number of pediatric head injuries caused by all types of off-road vehicles in the last few years. This suggests the need for recognition of this increasingly frequent mechanism of injury in the prophylaxis and treatment of head trauma in children.

\section{Injury Severity and Associated Injuries}

Of 83 head injured children $60.2 \%$ suffered loss of consciousness, and $2.4 \%$ presented early post-traumatic seizures. While these figures are comparable to results from other, larger series of all types of pediatric head injuries, off-road accidents lead to a much higher number of associated injuries. 26, 29-31 For instance associated limb fractures have been reported in $3-9.2 \%$ of head injuries, while it occurred in $84.3 \%$ of our cases, with multiple fractures in $35 \% .26 .27,29.32-34$ Similarly, associated visceral trauma has been reported from $1.7 \%$ to $5 \%$ in other series, ${ }^{26,27}$ while it occurred in $18 \%$ of our cases. Smaller series of pediatric head injuries caused by all-terrain vehicles have also shown a high number of associated injuries. 3.5

The severity of injuries in our cases was comparable to that reported for motorcycle accidents. ${ }^{11.25}$ Our study also showed a high number of associated spinal injuries (19\%), while these injuries usually amount to less than $0.5 \%$ in larger series of all types of pediatric head injuries. ${ }^{1.26 .29} \mathrm{Kantz}$ 's suggestion that motorized riders are more susceptible to spinal fractures has been confirmed by our series of off-road vehicle accidents. ${ }^{35}$ Furthermore this increased number of spinal fractures seems to be frequently associated with traumatic myelopathy. ${ }^{4}$

No conclusions on helmet protection for off-road vehicle users could be drawn from our study, as explicit information was only available for very few patients. As for the severity of associated injuries, it is unlikely that widespread use of helmets would have altered the findings. Legislation on the compulsory use of helmets for recreational off-road vehicle riders was only introduced in Manitoba in October, 1988.

Series involving all types of pediatric head injuries have reported variable mortality figures. $1.26,32,33,36$ This probably reflects differences in criteria for selection of cases. The $3.6 \%$ mortality encountered in our series of hospitalized children, was slightly higher than the $0.9-3 \%$ mortality rate reported in other larger series using similar criteria for selection of patients. ${ }^{26,29}$, $32,33,37$ This may have resulted from the higher number of associated injuries in our patients.

Our results indicate that the use of off-road vehicles by children is a frequent cause of severe head and associated injuries. The growing number of casualties urges the implementation of prophylactic nieasures, which could include: built-in cruisecontrol systems to adjust maximum speed according to age, reduction in power and size of vehicles, compulsory use of backed-seats and seat-belts, as well as confinement of recreational use of off-road vehicles to designated sites under legislated supervision.

\section{REFERENCES}

1. Annegers JF. The epidemiology of head trauma in children. In: Shapiro K, ed. Pediatric Head Trauma. New York: Futura Publ. 1983; 1-10. 
2. Annegers JF, Grabow JD, Kurland LT, et al. The incidence, causes, and secular trends of head trauma in Olmsted County, Minnesota 1935-1974. Neurology 1980; 30: 912-919.

3. Kriel RL, Sheehan M, Krach LE, et al. Pediatric head injury resulting from all-terrain vehicle accidents. Pediatrics 1986; 78: 933935.

4. Sneed RC, Stover SL, Fine PR. Spinal cord injury associated with all-terrain vehicle accidents. Pediatrics 1986; 77: 271-274.

5. Stevens WS, Rodgers BM, Newman BM. Pediatric trauma associated with all-terrain vehicles. Pediatrics 1986; 109: 25-29.

6. Balcerak JR, Pancione KL, States JD. Moped, minibike, and motorcycle accidents. NY State J Med 1978; 628-633.

7. Letts RM, Cleary J. The child and the snowmobile. Can Med Assoc J 1975; 113: 1061-1063.

8. Smith SM, Middaugh JP. Injuries associated with three-wheeled, all-terrain vehicles, Alaska, 1983 and 1984. JAMA 1986; 255: 2454-2458.

9. Accident Prevention Committee, Canadian Pediatric Society. Two-, three- and four-wheel unlicensed off-road vehicles. Can Med Assoc J 1987; 136: 119-120.

10. Charters AC, Schroedl G. Off-road vehicle accidents: a new spectrum of trauma. J Trauma 1978; 18: 596-600.

11. Clark DW, Morton JH. The motorcycle accident: a growing problem. J Trauma 1971; 11: 230-236.

12. Cogbrill TH, Landercasper J, Metheny JA. Three-wheeler accidents. JAMA 1985; 254: 1037.

13. Haynes CD, Stroud SD. Thompson CE. The three-wheeler (adult tricycle): an unstable, dangerous machine. J Trauma 1972; 26: 643-648.

14. Percy EC. The snowmobile: friend or foe? J Trauma 1972; 12: 444446.

15. Wiley JJ, Mercier P. Injuries to children from off-road vehicles. Ontario Med Rev 1985; 590-591.

16. Wiley JJ, McIntyre WM, Mercier P. Injuries associated with offroad vehicles among children. Can Med Assoc J 1986; 135: $1365-1366$

17. Cardoso ER, Del Bigio M, Schroder G. Cerebral elasticity and ventricular size. Part II. Age-related development of extracerebral fluid collections. In: Hoff JT, eds. Intracranial Pressure VII. Springer-Verlag. In press.

18. Golladay ES, Slezak JW, Mollitt DL, et al. The three-wheeler - a menace to the preadolescent child. J Trauma 1985; 25: 232-233.

19. Michaels E. ATV's: a new safety hazard. Can Med Ass J 1986; 134: $540-542$

20. Trager GW, Grayman G. Accidents and all-terrain vehicles. JAMA 1986; $255: 2160-2161$
21. Deppa RW. A discussion of the dynamic characteristics of all-terrain vehicles. United States Consumer Product Safety Commission, April 1984

22. Speca JM, Cowell HR. Minibike and motorcycle accidents in adolescents - a new epidemic. JAMA 1975; 232: 55-56.

23. Directorate for epidemiology: death certificate file, Washington, D.C. United States Consumer Product Safety Commission.

24. Westman JA, Morrow 111 G. Moped injuries in children. Pediatrics $1984 ; 74: 820-822$

25. Heilman DR, Weisbuch JB, Blair RW, et al. Motorcycle-related trauma and helmet usage in North Dakota. Ann Emerg Med 1982; II: 659-664.

26. Hendrick EB, Harwood-Hash DCF, Hudson AR. Head injuries in children: a survey of 4,465 consecutive cases at the Hospital for Sick Children, Toronto, Canada. Clin Neurosurg 1964; 11: 4665 .

27. Klonoff $\mathbf{H}$. Head injuries in children: predisposing factors accident conditions, accident proneness and sequelae. Am J Public Health 1971; 61: 2405-2417.

28. Cooper PR. Head injury. Baltimore: William \& Wilkins, 2nd ed $1987 ; 11$.

29. Ivan LP, Choo SH, Ventureyra ECG. Head injuries in childhood: I 2-year survey. Can Med Assoc J 1983; 128: 281-284.

30. Jennett B. Head injuries in children. Dev Med Child Neurol 1972. 14: 137-147.

31. Jennett B. Trauma as cause of epilepsy in childhood. Dev Med Child Neurol 1973; 15: 56-62.

32. Kraus JF, Fife D, Conroy C. Pediatric brain injuries: the nature, clinical course, and early outcomes in a defined United States population. Pediatrics 1987; 79: 501-507.

33. Kraus JF, Fife D, Cox P, et al. Incidence, severity and external causes of pediatric brain injury. Am J Dis Child 1986; 140: 687693.

34. Melchior JC. The incidence of head injuries in children. Acta Paediatr Scand 1961; 50: 47-50.

35. Krantz KPG. Head and neck injuries to motorcycle and moped riders - with special regard to the effect of protective helmets. Injury $1985 ; 16: 253-258$.

36. Miner ME, Kaufman HH, Graham SH. Head trauma in children does undetected DIC lead to higher mortality? J Pediatr 1982; 100: 687-691.

37. Klauber MR, Barrett-Connor E, Marshall LF, et al. The epidemiology of head injury. A prospective study of an entire community - San Diego County, California, 1978. Am J Epidemiol 1981: 113: 500-509. 